\title{
Using staffing ratios for workforce planning: evidence on nine allied health professions
}

\author{
Linda Cartmill ${ }^{1 \dagger}$, Tracy A Comans ${ }^{2 \dagger}$, Michele J Clark ${ }^{1 *}$, Susan Ash ${ }^{1}$ and Lorraine Sheppard ${ }^{3,4}$
}

\begin{abstract}
Background: Modern healthcare managers are faced with pressure to deliver effective, efficient services within the context of fixed budget constraints. Managers are required to make decisions regarding the skill mix of the workforce particularly when staffing new services. One measure used to identify numbers and mix of staff in healthcare settings is workforce ratio. The aim of this study was to identify workforce ratios in nine allied health professions and to identify whether these measures are useful for planning allied health workforce requirements.

Methods: A systematic literature search using relevant MeSH headings of business, medical and allied health databases and relevant grey literature for the period 2000-2008 was undertaken.

Results: Twelve articles were identified which described the use of workforce ratios in allied health services. Only one of these was a staffing ratio linked to clinical outcomes. The most comprehensive measures were identified in rehabilitation medicine.
\end{abstract}

Conclusion: The evidence for use of staffing ratios for allied health practitioners is scarce and lags behind the fields of nursing and medicine.

\section{Background}

Health care worldwide is a large and expensive industry for which there are high consumer expectations. As health care increasingly relies on expensive technologies and drugs, governments are under mounting pressure to find ways to contain costs. Managing staff costs has emerged as a major area of focus [1,2]. It has become apparent that there are service over-laps [3,4], and that staff allocation must be evidence-based $[5,6]$ and focused on the needs of the population serviced rather than continuing with traditional areas and modes of service [7-9]. The Australian Productivity Commission recently identified under-utilisation of the professional competencies of staff as an area of concern for the Australian health workforce [10].

When introducing new services and reviewing current service delivery models, managers must make decisions on what constitutes appropriate levels of staffing. Different methods such as ratios; where staff are provided in a

\footnotetext{
* Correspondence: mj.clark@qut.edu.au

† Contributed equally

'School of Public Health, Queensland University of Technology, Victoria Park Rd, Kelvin Grove, 4059, Brisbane, Australia

Full list of author information is available at the end of the article
}

set ratio per measure such as bed numbers or population; and staffing according to patient acuity (for acute care services) are methods used in health care services for determining appropriate staff levels. While models of this type have been used successfully with nursing [11-13], and medical specialty professions [14], what constitutes appropriate levels of staffing for allied health professionals (AHPs) is less clear.

An Australian study $[15,16]$ reviewed a number of workload capacity measures for use in estimating allied health staff requirements. Measures were categorised into ratiobased, procedure-based, care-based and diagnostic or casemix-based methodologies. The authors concluded that while the procedure-based method was the most widely used, overall the methodologies used in allied health workforce planning were poorly substantiated and rudimentary in nature.

Aims

The aim of this review was to identify what workforce ratios have been used in nine allied health professions and to identify whether these measures would be useful for planning allied health workforce requirements. 


\section{Method}

A systematic literature search was performed using medical, business and allied health databases to identify workplace ratios for nine identified allied health professions: audiology, dietetics and nutrition, exercise physiology, occupational therapy, podiatry, physiotherapy, psychology, social work, and speech pathology. It was anticipated few items would achieve level 1-3 evidence using recognised criteria [17]. Similarly, methodological diversity was expected. In order to capture all possible relevant material, searches were not limited to any particular study design. Material retrieved included controlled trials, narrative reviews, audits, opinions and editorials.

Articles were included if they were published between and including the years 2000-2008, were related to workplace ratios, were transferable to the Australian context (defined as being from a country meeting United Nations criteria for a developed economy [18]), and identified numbers of professionals per specified number of beds or outpatients. Articles were excluded if they were outside a developed world setting, conducted in a setting other than health care, were not in the English language, or were a paper concerning professions outside the nine identified allied health professions.

Medical subject headings (MeSH) were identified and selected in consultation with a specialist librarian. The following search terms were used: health manpower or health care reform or health resources or health services research or government or personnel management or workload or workforce or time management or quality of health care. These were used in conjunction with the term allied health and the names of the nine target allied health professions: allied health or audiolog* or dietician or dietitian or nutritionist or exercise physiolog* or occupational therap" or podiatr" or physiotherap" or physical therap" or psychologist or social worker or speech patholog* $^{*}$ or speech therap* or speech and language.

The databases examined included: Medline, Cinahl, ABI/Inform, Apais Health, Business Source, Embase, Meditext, OT Seeker, Psychinfo, and Pedro. In addition, electronic searches were conducted of Australian Health Review, Cochrane Library Economic Evaluation Database, website of Public Health Research Unit for the United Kingdom National Health Service (NHS), and the Service Delivery and Organisation Programme of the National Institute for Health Research-a research institute associated with the NHS website for the Joanne Briggs Foundation.

Requests were made to the professional bodies of the nine professional associations in Australia for any written documentation on workplace ratios and their web-sites were checked for published information. A reference group for the project included six of the nine professional groups and members were asked to search informal and grey literature (e.g. government reports and profession specific reports) relevant to their profession. Manual searching of reference lists of key articles and items recommended by informal professional contacts and peers produced three additional relevant references.

The initial strategy produced 1207 titles which were screened by title and abstract for compliance with inclusion and exclusion criteria; 989 papers were excluded. Where abstracts were not available or content uncertain, the full text article was obtained. 218 abstracts or full text articles were imported into Endnote. A second more detailed review was conducted and inclusion and exclusion criteria were applied independently by the two authors (LJC and TAC) from which 30 relevant articles were extracted. Exclusions were reviewed together and disagreements resolved by discussion after viewing the full text article where necessary. A version of the CriSTAL checklist for evaluating the quality of various research designs $[19,20]$ was used to appraise included papers for their quality. After training in use of the appraisal tool, twenty articles were randomly selected and appraised by both LJC and TAC. An inter-rater correlation coefficient of $83 \%$ was achieved; LJC completed remaining appraisals. The review process is outlined in Figure 1.

Paper quality was determined by the presence or absence of study characteristics of: reliable data collection, adequate response rate, representativeness of participants, completeness of results, methodological limitations, and honest and objective conclusions.

\section{Results}

The literature review identified 12 papers where figures were given for the ratio of different AHPs to bed or patient numbers. Table 1 briefly outlines the papers and gives the quality criteria score obtained from Section B of the CriSTAL checklist. Only one paper scored six out of a possible seven on study quality criteria [20]. Highly varied research methods and uncertain study quality were consistent across the professions. Physiotherapy was the most frequently recorded profession appearing in eight of the publications.

Several papers demonstrated ratios by work setting rather than profession such as, adult rehabilitation [21-24] and emergency department [25,26]. Suggested ratios were also described for specific conditions, e.g. obesity [27] and kidney disease [28]. The ratios for each profession varied between the different settings. Additionally ratios varied between inpatient and community settings.

The methods applied in developing the ratios were derived from four main approaches: consensus, 


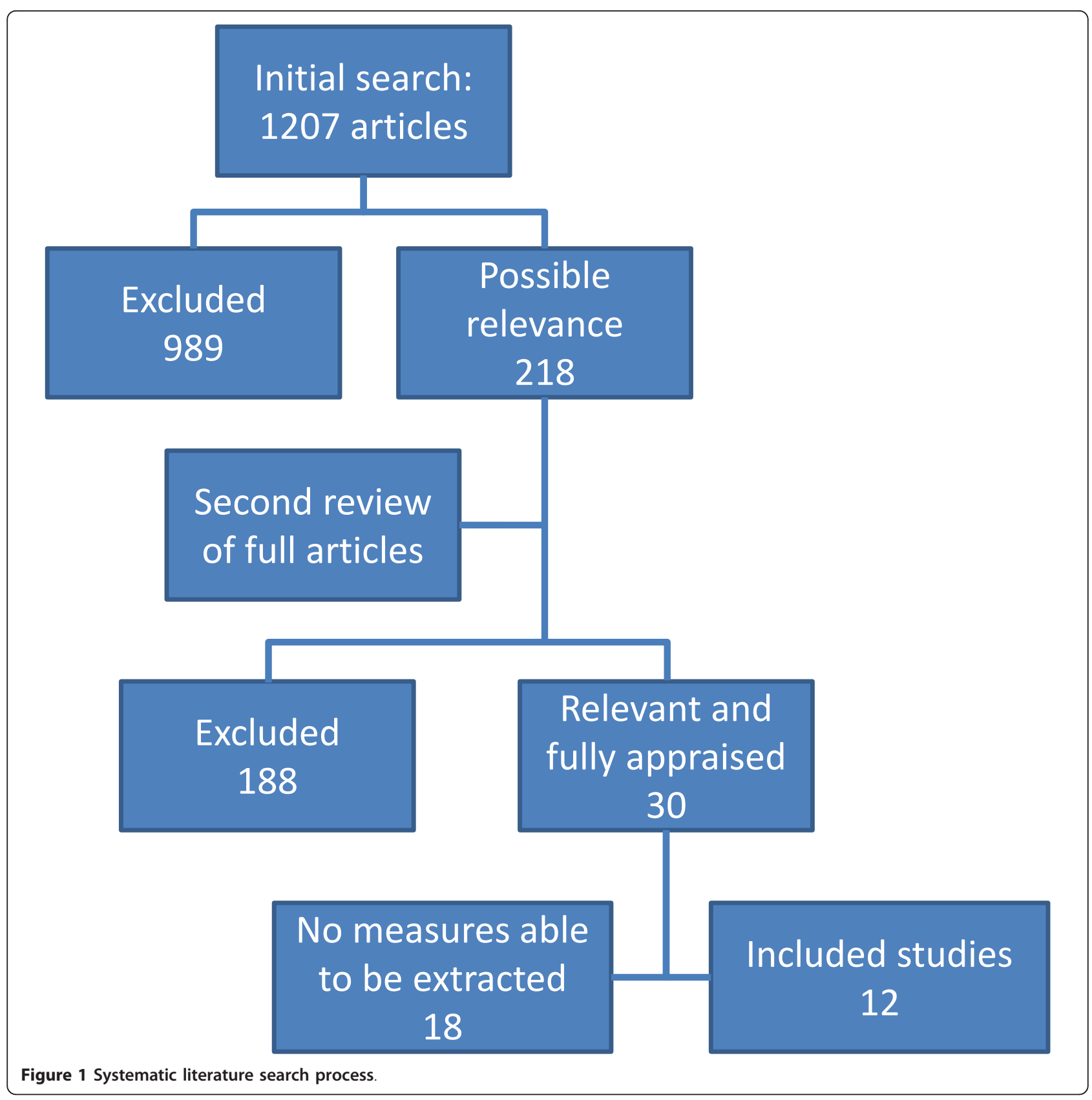

experimental trial, current clinical practice and those developed using staff classifications.

\section{Consensus}

Consensus rather than observation or other means was used by six papers. Consensus came from working groups or committees. These papers presented standards [22], recommendations [21,25], and position statements [25,26,29] or benchmarks [30]. However, the ratios presented even varied within papers rather than clinical setting alone, with ratios varying to almost double $[21,22]$, demonstrating the variability and difficulty of arriving at recommended ratios. Comparisons between recommended ratios within the same clinical setting, for example emergency departments $[25,26]$, varied greatly. These papers highlight the difficulty of defining ratios without contextual role descriptions, for example, the roles of physiotherapists in the emergency department may vary from triage, undertaking first contact responsibilities or more conventional practice of referral from medical practitioners. In contrast, the Dieticians Association of Australia stated currently there is no standard to describe the ideal dietetic workforce in Australia [31]. 
Table 1 Description of the included papers

\begin{tabular}{|c|c|c|c|c|c|}
\hline Reference & $\begin{array}{l}\text { Quality } \\
\text { score* }\end{array}$ & Study Type & Country & Setting & Brief Description \\
\hline $\begin{array}{l}\text { AH Rehab CC } \\
\text { (2007)[21] }\end{array}$ & 1 & Focus group & Australia & Rehabilitation & $\begin{array}{l}\text { Consensus statement on required numbers of allied health to staff rehabilitation facilities treating various } \\
\text { categories of patients }\end{array}$ \\
\hline $\begin{array}{l}\text { Aust. Fac. Rehab. } \\
\text { Med. (2005) [22] }\end{array}$ & 2 & $\begin{array}{l}\text { Non-systematic } \\
\text { synthesis }\end{array}$ & Australia & Rehabilitation & Discussion paper estimating staffing numbers required for rehabilitation facilities \\
\hline $\begin{array}{l}\text { Br Diabetic Assn } \\
\text { (1999) [29] }\end{array}$ & 1 & Position statement & Britain & $\begin{array}{l}\text { Diabetes } \\
\text { services }\end{array}$ & Provides recommendations for core staffing levels required for specialist diabetes services. \\
\hline $\begin{array}{l}\text { Burton et al (2005) } \\
\text { [33] }\end{array}$ & 2 & Audit & Australia & Rehabilitation & $\begin{array}{l}\text { Audit of psychologist numbers in ten hospitals in the rehabilitation sector of Victoria. All services reported } \\
\text { under-staffing. }\end{array}$ \\
\hline Christie (2006) [30] & 2 & Audit/benchmark & Canada & $\begin{array}{l}\text { Acute } \\
\text { hospital }\end{array}$ & $\begin{array}{l}\text { Identification of physiotherapy and occupational therapy FTEs per bed over time in medical and surgical } \\
\text { wards. }\end{array}$ \\
\hline Gill (2007) [28] & 2 & Model & Australia & $\begin{array}{l}\text { Chronic } \\
\text { kidney } \\
\text { disease }\end{array}$ & $\begin{array}{l}\text { Model for provision of community based services for patients with chronic kidney disease via extended scope } \\
\text { roles for dieticians and nurses. }\end{array}$ \\
\hline $\begin{array}{l}\text { Henley et al } \\
\text { (2006) [25] }\end{array}$ & 2 & $\begin{array}{l}\text { Non-systematic } \\
\text { synthesis }\end{array}$ & $\begin{array}{l}\text { Australia and } \\
\text { New Zealand }\end{array}$ & $\begin{array}{l}\text { Emergency } \\
\text { department }\end{array}$ & $\begin{array}{l}\text { Provides guidelines to the function and operations of acute MAPUs attached to hospital emergency } \\
\text { departments. }\end{array}$ \\
\hline $\begin{array}{l}\text { McMillan \& Ledder } \\
\text { (2001) [23] }\end{array}$ & 4 & Audit & Britain & $\begin{array}{l}\text { Neuro- } \\
\text { rehabilitation }\end{array}$ & $\begin{array}{l}\text { Survey of staffing in adult neuro-rehabilitation teams in south-east England. High incidence of staff stress due } \\
\text { to the case-loads. Little is offered for those with psycho-social disability for example few teams contain } \\
\text { neuro-psychologists. }\end{array}$ \\
\hline $\begin{array}{l}\text { Meyer et al (2002) } \\
\text { [32] }\end{array}$ & 6 & Audit & Australia & All & University of Wollongong study of the dietetic workforce of New South Wales from 1984 to 2000. \\
\hline $\begin{array}{l}\text { Mudge, et al } \\
\text { (2006) [24] }\end{array}$ & 4 & Controlled trial & Australia & $\begin{array}{l}\text { Acute } \\
\text { hospital }\end{array}$ & $\begin{array}{l}\text { Controlled trial in an acute general setting of the effect of increased levels of multidisciplinary intervention. } \\
1538 \text { medical in-patients were assigned either to routine care or to care with three times the amount of } \\
\text { allied health professional time. Resulted in significantly reduced in-hospital mortality and functional decline } \\
\text { and improvement in patients' ratings of their health status }\end{array}$ \\
\hline $\begin{array}{l}\text { PA Hospital (2004) } \\
\text { [26] }\end{array}$ & 2 & Pre-post study & Australia & $\begin{array}{l}\text { Emergency } \\
\text { department }\end{array}$ & $\begin{array}{l}\text { In house survey of a trial of the use of AHPs (OTs, PTs and STs) in the Emergency Dept of a tertiary hospital } \\
\text { for a period of } 4 \text { months over winter. Project made considerable cost savings for the hospital by avoiding in- } \\
\text { patient admission for } 117 \text { patients over the period of the trial. }\end{array}$ \\
\hline $\begin{array}{l}\text { Ridoutt et al } \\
\text { (2006) [15] }\end{array}$ & 3 & $\begin{array}{l}\text { Literature review and } \\
\text { focus group analysis }\end{array}$ & Australia & All & $\begin{array}{l}\text { Aimed to identify current methods of quantifying AHP workload capacity and to profile the AHP workforce } \\
\text { requirements. Recommended the use of a procedures based workload measurement tool. This tool would be } \\
\text { useful in settings with set or routine treatments e.g. rehabilitation, community settings. }\end{array}$ \\
\hline
\end{tabular}

* CriSTAL Appraisal Score Section B (score out of 7)

$\mathrm{AHP}=$ allied health professional; $\mathrm{FTE}=$ full time equivalent; $\mathrm{MAPU}=$ medical assessment and planning unit; $\mathrm{OT}=$ occupational therapist; $\mathrm{PT}=$ physiotherapist; $\mathrm{SP}=$ speech pathologist. 


\section{Experimental trial}

Ratios derived from experimental trial were found in one paper. A controlled trial [24] studied the effects of a significantly increased level of interventions by AHPs. Outcome data of inpatient mortality, functional decline, patient reports of health status and length of stay were collected. The authors compared the increased cost of three times more AHPs with an unconvincing economic analysis of these outcomes to arrive at recommended ratios of AHP required for elderly patients with complex medical conditions.

\section{Current clinical practice}

Current clinical ratios were collected by survey by dieticians [32] and psychologists [33]. Each reported current staffing rates as insufficient. An English paper surveying neuro-rehabilitation teams [23] also reported a high incidence of staff stress due to the size and nature of the case-load.

\section{Staff classifications}

Finally, staff classifications were used to develop a ratio system which is independent of patient characteristics [15]. The staff classifications were used to present the possible clinical load as a percentage of full time equivalent (FTE) (85\% reducing to 60\%), with higher classifications or more experienced staff expected to have more managerial responsibilities and less clinical contact.

\section{Discussion}

Table 2 indicates that there is a scarcity of research into staffing ratios for allied health professions. Only seven articles giving FTEs from functioning clinical examples could be located and potentially used in workforce planning. The usefulness of these is limited as they cover such a diverse range of settings and patient groups.

Within the Emergency Department area, for instance, it is difficult to compare the Princess Alexandra Hospital (PAH) figures [26] with those of the three described by Henley [25]. Where the PAH paper was of a four month trial over the winter period, the Henley paper describes the experiences of three diverse, ongoing, Medical Assessment and Planning Units (MAPUs). It is unclear how comparable in size are the Emergency Departments of $\mathrm{PAH}$ and the three hospitals of the Henley document; it is also unclear whether the clinical roles performed by the AHPs are comparable across sites for this new area of practice.

Of the five reports prepared by professional groups there are some similarities between the figures produced by the Allied Health in Rehabilitation group [21] and those produced by the Australasian Faculty of Rehabilitation Medicine [22]. It is noteworthy that the empirical Canadian experience [30] supports the Australian figures in the area of orthopaedics, while the Canadian figures for cardio-vascular wards are significantly lower than those recommended by the Allied Health in Rehabilitation group. However, without further information on the roles of staff or clinical outcome measures, it is not possible to adequately compare the ratios.

The Austin Hospital figures [15] for physiotherapy staff ratios enable comparison with those provided by the two professional groups in the area of neurology. The Austin figure of 0.9 FTE physiotherapists concurs with those of the Australian Faculty of Rehabilitation Medicine figures for rehabilitation neurology wards and is considerably less than the 1.5 FTE recommended by the Allied Health in Rehabilitation Collaborative Committee. It is uncertain if this represents different clinical practice or alternatively a difference of opinion between management and clinical therapists about appropriate staffing levels.

Only one paper [24] provided a link between staff FTEs and clinical outcomes, thus establishing an evidence base to support staffing numbers. The clinical intervention in that paper included increasing AHP staff, re-structuring teams and standardising communication systems. The results indicated a non-statistically significant trend towards a reduction in length of stay and in-patient beduse which was seen as offsetting the cost of increased staffing levels. In addition, in-hospital mortality and functional decline were both significantly reduced.

While one paper [30] differentiated between AHP numbers required for general geriatric rehabilitation and stroke rehabilitation, there is no such division according to caseload in the figures provided by any of three other papers which also addressed rehabilitation staff ratios. Such inconsistencies make comparisons problematic.

\section{Conclusions}

Use of staffing ratios to determine appropriate staff numbers can be a useful tool to guide service planning and delivery. This tool has been successfully used in nursing particularly in the acute care setting $[13,14]$. This review aimed to find out if allied health workforce ratios existed and if these ratios could be used in allied health service planning. However, there were few examples of staffing ratios found for AHPs and only one of these was a staffing ratio linked to clinical outcomes. From the papers found, it may be possible to apply ratios in the specific specialist areas of rehabilitation and MAPUs for allied health workforce planning. It is not possible from the evidence presented to use workforce ratios to plan for allied health requirements in general settings such as a general hospital or a community setting.

As the population ages and the incidence of chronic disease rises there will be increased demand for allied health services. Health managers and policy makers will need access to appropriate evidence based research to 
Table 2 Summary of the published ratios for allied health professionals

\begin{tabular}{|c|c|c|c|c|c|c|c|c|}
\hline & $\begin{array}{l}\text { Physio- } \\
\text { therapist }\end{array}$ & $\begin{array}{c}\text { Occ. } \\
\text { therapist }\end{array}$ & $\begin{array}{l}\text { Speech } \\
\text { therapist }\end{array}$ & $\begin{array}{l}\text { Social } \\
\text { worker }\end{array}$ & $\begin{array}{l}\text { Clinical } \\
\text { Psych. }\end{array}$ & $\begin{array}{l}\text { Neuro- } \\
\text { Psych }\end{array}$ & Dietitian. & $\begin{array}{c}\text { Podiat- } \\
\text { rist }\end{array}$ \\
\hline \multicolumn{9}{|c|}{ Hospital Setting } \\
\hline \multicolumn{9}{|l|}{$\begin{array}{l}\text { Allied Health in Rehab. CC (2007) } \\
\text { [21] }\end{array}$} \\
\hline Amputat.* & 1.5 & 1.0 & 0.025 & 0.6 & 0.5 & 0.025 & 0.4 & 0.5 \\
\hline Arthritis & 1.0 & 0.8 & 0.025 & 0.2 & 0.025 & - & 0.4 & 0.1 \\
\hline Burns* & 2.0 & 2.0 & 0.2 & 1.2 & 1.0 & - & 0.4 & 0.025 \\
\hline Cardiac & 0.75 & 0.5 & 0.025 & 0.25 & 0.025 & - & 0.4 & 0.1 \\
\hline Head Inj.* & 1.5 & 1.5 & 1.5 & 1.2 & 0.2 & 1.0 & 0.5 & 0.025 \\
\hline Maj.Mult.Trauma & 1.25 & 1.2 & 0.2 & 0.6 & 0.025 & 0.025 & 0.4 & 0.025 \\
\hline Neurol. & 1.5 & 1.5 & 1.5 & 1.0 & 0.2 & 0.6 & 0.5 & 0.2 \\
\hline Orthopaed. & 1.0 & 0.8 & 0.1 & 0.4 & 0.2 & - & 0.4 & 0.3 \\
\hline Pain & 1.25 & 1.0 & 0.025 & 0.5 & 0.5 & - & 0.4 & 0.025 \\
\hline Pulmonary & 0.75 & 0.75 & 0.1 & 0.25 & 0.025 & - & 0.4 & 0.1 \\
\hline Spinal* & 2.0 & 2.0 & 0.25 & 1.2 & 0.5 & 0.1 & 0.4 & 0.2 \\
\hline \multicolumn{9}{|l|}{ Aust. Fac. R. Med. (2005) [22] } \\
\hline Amputat. Acute & 1.5 & 1.0 & - & & 0.5 & - & & \\
\hline Neurol." & 1.5 & 1.5 & 1.5 & & 0.5 & 0.5 & & \\
\hline Orthopaed. " & 1.25 & 0.8 & - & & 0.2 & - & & \\
\hline Spinal " & 2.0 & 2.0 & 0.25 & & 0.5 & - & & \\
\hline $\mathrm{TBI} "$ & 1.5 & 1.8 & 1.5 & & 0.7 & 0.5 & & \\
\hline Amputat. Rehab & 0.7 & 0.5 & - & & 0.1 & - & & \\
\hline Neurol. " & 0.9 & 1.0 & 0.75 & & 0.5 & 0.5 & & \\
\hline Orthopaed. " & 0.7 & 0.3 & - & & 0.2 & - & & \\
\hline Spinal " & 0.9 & 1.0 & - & & 0.5 & - & & \\
\hline $\mathrm{TB}{ }^{\prime \prime}$ & 0.9 & 1.5 & 1.0 & & 0.5 & 0.5 & & \\
\hline Burton (2007) [33] & & & & & $0.15-0.3$ & $\begin{array}{c}0.05 \text { to } \\
0.5\end{array}$ & & \\
\hline \multicolumn{9}{|l|}{ Christie (2006) [30] } \\
\hline Gen. Surg. & 0.3 & 0.1 & & & & & & \\
\hline Orthopaed. & 1.0 & 1.0 & & & & & & \\
\hline Cardiovasc. & 0.9 & 0.1 & & & & & & \\
\hline Medical & 0.5 & 0.3 & & & & & & \\
\hline Rehab. (Geriatric) & 0.5 & 0.3 & & & & & & \\
\hline Rehab. (Stroke) & 1.2 & 1.0 & & & & & & \\
\hline \multicolumn{9}{|l|}{ Emergency Depts. } \\
\hline Bris PAH (2004) [26] & $2.5 \mathrm{AHP}$ & & & & & & & \\
\hline $\begin{array}{l}\text { MAPU (Henley) (2006) [25] (25 } \\
\text { bed) }\end{array}$ & 0.25 & 0.5 & 0.2 & 0.5 & & & & \\
\hline \multicolumn{9}{|l|}{ Meyer (2002) [32] } \\
\hline Hosp. Urban/Rural & & & & & & & $0.123 / 0.067$ & \\
\hline \multicolumn{9}{|l|}{ Mudge (2006) [24] } \\
\hline \multicolumn{9}{|l|}{ Complex Medical } \\
\hline Intervention Gp. & 0.4 & 0.4 & 0.2 & 0.4 & & & 0.16 & \\
\hline Usual Care Gp. & 0.12 & 0.1 & 0.06 & 0.16 & & & 0.08 & \\
\hline \multicolumn{9}{|l|}{$\begin{array}{l}\text { Ridoutt (2006) [15] quoting Austin } \\
\text { Hosp figures }\end{array}$} \\
\hline ICU & 2.0 & & & & & & & \\
\hline Neurol. & 0.9 & & & & & & & \\
\hline Gen. Rehab. & 1.2 approx & & & & & & & \\
\hline Unnamed Priv. Hosp All beds & $\begin{array}{l}0.92 \text { AHP hrs/ } \\
\text { bd.dy }\end{array}$ & & & & & & & \\
\hline
\end{tabular}


Table 2 Summary of the published ratios for allied health professionals (Continued)

\begin{tabular}{|c|c|c|c|c|}
\hline \multicolumn{5}{|c|}{ Community Setting } \\
\hline Br. Diabetes Assn. (1999) [29]/100 000 & & & 0.6 & 0.8 \\
\hline Gill (2007) [28] & $1: 70 \mathrm{pts}$ & $1: 500 \mathrm{pts}$ & $\begin{array}{r}: 80-120 p \\
75 p \\
\end{array}$ & \\
\hline McMillan \& Ledder (2001) [23]/100 000 & \multicolumn{4}{|c|}{1.5 community team professionals } \\
\hline Meyer (2002) [32] Urban/Rural/100 000 & & & \multicolumn{2}{|c|}{$0.093 / 0.082$} \\
\hline
\end{tabular}

Figures are per 10 beds unless otherwise stated

* Denotes specialist unit

guide workforce planning to best meet community health needs. This review has found that research on staffing ratios for allied health practitioners is scarce and lags behind the fields of nursing and medicine. There is little data available on allied health requirements in general hospital settings such as orthopaedics and surgery and also in general community settings. This review highlights the need for further research on staffing ratios and their relationship to health outcomes across both hospital and community settings.

\section{Acknowledgements}

This project was funded by the Allied Health Workforce Advisory and Coordination Unit, Queensland Health. All researchers involved in this study were independent of the funders and were not influenced in any way by the funding organisation. The views expressed are those of the authors and do not necessarily reflect those of the funder.

The project group advising and assisting the publishing authors consisted of: Dr Kirsten McKenzie, psychologist, School of Public Health, QUT, Dr Lloyd Reed, podiatrist, School of Public Health, Professor Lorraine Sheppard, physiotherapist, School of Health Sciences, University of South Australia and James Cook University, Dr Fiona Barnett, exercise physiologist, School of Public Health, James Cook University. The project was also assisted by research assistant, Samantha Streiner.

\section{Author details}

${ }^{1}$ School of Public Health, Queensland University of Technology, Victoria Park Rd, Kelvin Grove, 4059, Brisbane, Australia. ${ }^{2}$ School of Medicine, Griffith University, University Drive, Meadowbrook, 4131, Brisbane, Australia. ${ }^{3}$ Division of Health Sciences, School of Health Sciences, The University of South Australia, Adelaide, Australia. ${ }^{4}$ School of Public Health, Tropic Medicine \& Rehabilitation Sciences, James Cook University, Townsville, 4811, Australia.

\section{Authors' contributions}

LC conceived the research plan, undertook the systematic literature search and review and drafted the manuscript. TC conceived the research plan, undertook the systematic literature search and review and edited the final manuscript. MC, SA and LS contributed to the research plan and provided expert review and editing of the content. All authors approved the final manuscript.

\section{Competing interests}

The authors declare that they have no competing interests.

Received: 25 October 2010 Accepted: 1 February 2012

Published: 1 February 2012

\section{References}

1. Moran $\mathrm{L}$, et al: Cost calculation and prediction in adult intensive care: $\mathrm{A}$ ground-up utilization study. Anaesthesia and Intensive Care 2004, 32(6):787-797.
2. Harrison FG, Kuhlemeier KA: How do skilled nursing rehabilitation managers track efficiency and costs? Journal Of Allied Health 2001, 30(1):43-47.

3. Booth J, Hewison A: Role overlap between occupational therapy and physiotherapy during in-patient stroke rehabilitation: an exploratory study. Journal Of Interprofessional Care 2002, 16(1):31-40.

4. Buchan J, Dal Poz MR: Skill mix in the health care workforce: reviewing the evidence. Bulletin Of The World Health Organization 2002, 80(7):575-580.

5. Grimmer K: Providing evidence of good allied health care for the veteran population: Development of a unique management system. Journal of Allied Health 2002, 31(1):15.

6. Kumar S: Quality in allied health service delivery: rhetoric versus reality? Australasian Epidemiologist 2004, 11(2):45-7.

7. Andrews $\mathrm{G}$, Titov $\mathrm{N}$ : Changing the face of mental health care through needs-based planning. Australian Health Review 2007, 31:5122.

8. Segal L, Dalziel K, Bolton T: A workforce model to support the adoption of best practice in chronic diseases-a missing piece in clinical implementation. Implementation Science 2008, 3(35):1-10.

9. Tweeddale $\mathrm{M}$, et al: A Model for Demand Management. National Allied Health Conference Adelaide; 2003, 1-12.

10. Australian Government Productivity Commission: Australia's Health Workforce Canberra; 2005, 1-204.

11. Buchan J: A certain ratio? The policy implications of minimum staffing ratios in nursing. J Health Serv Res Policy 2005, 10(4):239-44.

12. Dimick JB, et al: Effect of nurse-to-patient ratio in the intensive care unit on pulmonary complications and resource use after hepatectomy. Am J Crit Care 2001, 10(6):376-82.

13. Romito D: Developing a staffing matrix using CMI as acuity indicator. Rehabil Nurs 2006, 31(3):102-5, 122.

14. Shannon EA, et al: Developing metrics for hospital medical workforce allocation. Aust Health Rev 2007, 31(3):411-21.

15. Ridoutt L, Schoo A, Santos T: Workload Capacity Measures for Use in Allied Health Workforce Planning. Victoria Department of Human Services; 2006, 1-62.

16. Schoo A, et al: Workload capacity measures for estimating allied health staffing requirements. Australian Health Review 2008, 32(3):548-558.

17. Ho PM, Peterson PN, Masoudi FA: Evaluating the evidence: is there a rigid hierarchy? Circulation 2008, 118(16):1675-84

18. Composition of macro geographical (continental) regions, geographical sub-regions, and selected economic and other groupings. 2008, [cited 20106 July]; Available from: http://unstats.un.org/unsd/methods/m49/ m49regin.htm\#developed.

19. Booth A, Brice A: Clear-cut?: facilitating health librarians to use information research in practice. Health Information and Libraries Journal 2003, 20(1):45-52.

20. Glynn L: A critical appraisal tool for library and information research. Library Hi Tech 2006, 24(3):387-99.

21. Allied Health in Rehabilitation Consultative Committee: Guidelines for Allied Health: Resources required for the provision of Quality Rehabilitation Services-Version 10 July 2007. 2007, 1-16.

22. Australasian Faculty of Rehabilitation Medicine: Standards 2005: Adult Rehabilitation Medicine Services in Public and Private Hospitals.Edited by: Royal Australasian College of Physicians. Sydney; 2005:1-12.

23. McMillan TM, Ledder $\mathrm{H}$ : A survey of services provided by community neurorehabilitation teams in south east England. Clinical Rehabilitation 2001, 15(6):582-588. 
24. Mudge A, et al: Controlled trial of multidisciplinary care teams for acutely ill medical inpatients: enhanced multidisciplinary care. Internal Medicine Journal 2006, 36:558-563.

25. Henley J, et al: Standards for Medical Assessment and Planning Units in Public and Private Hospitals: Position Statement of the Internal Medicine Society of Australia and New Zealand. IMSANZ Medical Assessment and Planning Unit Working Group; 2006.

26. Princess Alexandra Hospital Health Service: Allied Health Emergency Department Project: Final Status Report. PA Hospital Health Service District Brisbane; 2004, 1-27.

27. Christie HJ: Measuring the impact of bariatric patients in acute care. International Journal of Therapy \& Rehabilitation 2008, 15(3):112-113.

28. Gill E, et al: Potential for extended scope case management roles for dietitians in chronic kidney disease community management programs. Queensland University of Technology Institute of Health and Biomedical Innovation: Brisbane; 2007, 1-29.

29. British Diabetic Association: Recommendations for the structure of specialist diabetes care services. 1999, 8/1/2009; Available from: www. diabetes.org.uk.

30. Christie H, Grimwood M: Staffing: Can Physiotherapists and Occupational Therapists predict EFT per bed in acute care facilities? The Leading Edge 2006, 32:1-15

31. Dietitians Association of Australia: Dietitians Association of Australia Response to "The Health Workforce" Issues Paper. 2005, 10/11/2008; Available from: www.daa.asn.au/.

32. Meyer R, Gilroy R, Williams P: Dietitians in New South Wales: workforce trends 1984-2000. Australian Health Review 2002, 25(3):122-130.

33. Burton C, Murphy G, Smith-Tappe G: Workforce survey of psychologists in the rehabilitation sector-Victoria. 2005, 1-5.

doi:10.1186/1478-4491-10-2

Cite this article as: Cartmill et al: Using staffing ratios for workforce planning: evidence on nine allied health professions. Human Resources for Health 2012 10:2.

\section{Submit your next manuscript to BioMed Central and take full advantage of:}

- Convenient online submission

- Thorough peer review

- No space constraints or color figure charges

- Immediate publication on acceptance

- Inclusion in PubMed, CAS, Scopus and Google Scholar

- Research which is freely available for redistribution

Submit your manuscript at www.biomedcentral.com/submit 